\title{
Paediatric desmoplastic medulloblastoma - Surgical treatment, adjuvant therapy, outcome survival (case series study)
}

\author{
Raad Ahmed Hussein ${ }^{1}$, Muhammed Hameed Faeadh Al-Jumaily², Rana Hani Mohammed \\ Ali Al-Shaikh Hamed ${ }^{3}$, Asaad F. Albayati ${ }^{4}$ \\ ${ }^{1}$ Department of Internal Medicine, Neurology Unit, College of Medicine, \\ Aliraqia University, Baghdad, Iraq \\ ${ }^{2}$ Department of Surgery, College of Medicine, Aliraqia University, Baghdad, Iraq \\ ${ }^{3}$ Department of Pharmacology, College of Medicine, Aliraqia University, Baghdad, Iraq \\ ${ }^{4}$ Department of Pathology, College of Medicine, Aliraqia University, Baghdad, Iraq
}

\begin{abstract}
Background. Desmoplastic medulloblastoma is a common adult cerebellar tumor. It has better than classic medulloblastoma outcome. This is a case series study followed up the cases of paediatric desmoplastic medulloblastoma and their treatment outcome and prognosis.

Aim of study. Evaluation of the management and outcome survival, of this uncommon paediatric desmoplastic variety of medulloblastoma.

Methods. 20 paediatric patients of desmoplastic medulloblastoma were collected between 2008 and 2017; 12 were males and 8 were females. All the cases were treated firstly for hydrocephalus followed by craniotomy and tumor resection.

Results. The children were treated medically and surgically; the desmoplastic variant of medulloblastoma demonstrated better than classic medulloblastoma outcome. Median follow-up was 24 months. The younger the child, the better the outcome. 4 patients died from recurrent medulloblastoma. Bad outcomes were in recurrent and disseminated medulloblastomas.

Conclusions. Surgical resection followed by chemotherapy and/or radiotherapy give better outcome in desmoplastic medulloblastoma patients comparing with the classical medulloblastoma.
\end{abstract}

Keywords: medulloblastoma, desmoplastic medulloblastoma, children

\section{INTRODUCTION}

Medulloblastoma (WHO grade IV brain tumor) is the second most common after pilocytic astrocytoma, embryonal neuroepithelial posterior fossa cerebellar tumour in children, with an inherent tendency to metastasize via cerebrospinal fluid (CSF) pathways. The main histological types are the "classical" and "desmoplastic" medulloblastoma. The desmoplastic medulloblastoma are frequent in adults (1). These tumors occur mostly in childhood and account for $25 \%$ of paediatric brain tumors and less than $1 \%$ of all CNS tumors in the adult population (2). The tumor arises from the embryonic cells remnants in the cerebellar external granular layer (3). It has 2 peaks of incidence, in the first decade and in the early twenties (4). Desmoplasia may occur in any medulloblastoma type and may be normal leptomeningeal invasion reaction and $95 \%$ of medulloblastomas are classic or desmoplastic tumors $(5-10,11)$. The widespread nodularity in infantile desmoplastic medulloblastoma and the medulloblastoma with extensive nodularity (MBEN), is associated with a good prognosis $(12,13)$, while the extensive nuclear pleomorphism is characteristic of aggressive anaplastic medulloblastoma $(14,15)$. The WHO classified medulloblastoma into 5 subtypes: i) classic $(66 \%)$, ii) desmoplastic/nodular 
$(\mathrm{D} / \mathrm{N})(12 \%)$, iii) MBEN (3\%), iv) large cell (2$4 \%)$ and v) anaplastic $(15 \%)(4,16,17,18)$. The 2016 WHO tumor classification classified medulloblastoma into: the Wingless (WNT), Sonic Hedgehog ( $\mathrm{SHH})$, group 3, and group 4 (19). The desmoplastic/nodular medulloblastoma is seen in the SHH subgroup and has a good-to-intermediate prognosis. The WNT subgroup has the best survival rate followed by $\mathrm{SHH}$ and group 4 whereas group 3 has the worst prognosis and high metastasis rate at the time. The etiology of medulloblastoma is unknown, some genetic disorders are associated with medulloblastoma (Gorlin syndrome, Turcot syndrome, Li-Fraumeni syndrome [LFS]) (20). Medulloblastomas can occur throughout the CNS as a supratentorial PNETs or pineoblastomas in the pineal region or retinoblastomas. Dissemination occurs throughout the subarachnoid space (21).

\section{PATIENTS AND METHODS}

Twenty children with cerebellar desmoplastic medulloblastoma was collected and followed up between 2008 and 2017 and confirmed histopathologically as desmoplastic medulloblastoma. The cases were collected from Tikreet teaching hospital, Al-Shaek Zaed teaching hospital, Al-Falluja teaching hospital in Iraq; and Ibn Al-Hytham teaching hospital in Amman-Jordan. Twelve patients were male $(60 \%)$, and 8 were female $(40 \%)$. The ages range was from 3 to 11 years. All children were presented with: headaches, nausea and vomiting, gait unsteadiness, cerebellar signs including nystagmus, dysmetria, dysdiadokokinesis, ataxia, intentional tremor. All cases were investigated with contrast enhanced CT and/or MRI scan imaging and revealed well enhanced cerebellar tumors with variable degree of hydrocephalus.

\section{RESULTS}

All children were investigated with contrast enhanced CT and/or MRI scan of the neuraxis and revealed vividly enhanced cerebellar tumors with hydrocephalus. Some of the cases were focal multinodular cerebellar hemispheric tumors and others were midline vermian and $4^{\text {th }}$ ventricular tumors. The lesions varied in sizes from $2-5 \mathrm{~cm}$. At surgery, a midline posterior fossa craniectomy/craniotomy and tumor resection were performed under microscope, after initial ventriculoperitoneal shunt or $3^{\text {rd }}$ ventriculostomy for hydrocephalus. The histopathology revealed desmoplastic medulloblastoma. All patients older than 3 years were sent for brain and neuraxis irradiation then chemotherapy. The follow-up time postoperatively was 24 months. Four patients developed transient postoperative akinetic mutism which improved after few weeks. All those 4 patients were operated for midline vermian $/ 4^{\text {th }}$ ventricular medulloblastoma. The neuropathological diagnosis was desmoplastic medulloblastoma, some specimens with poorly differentiated

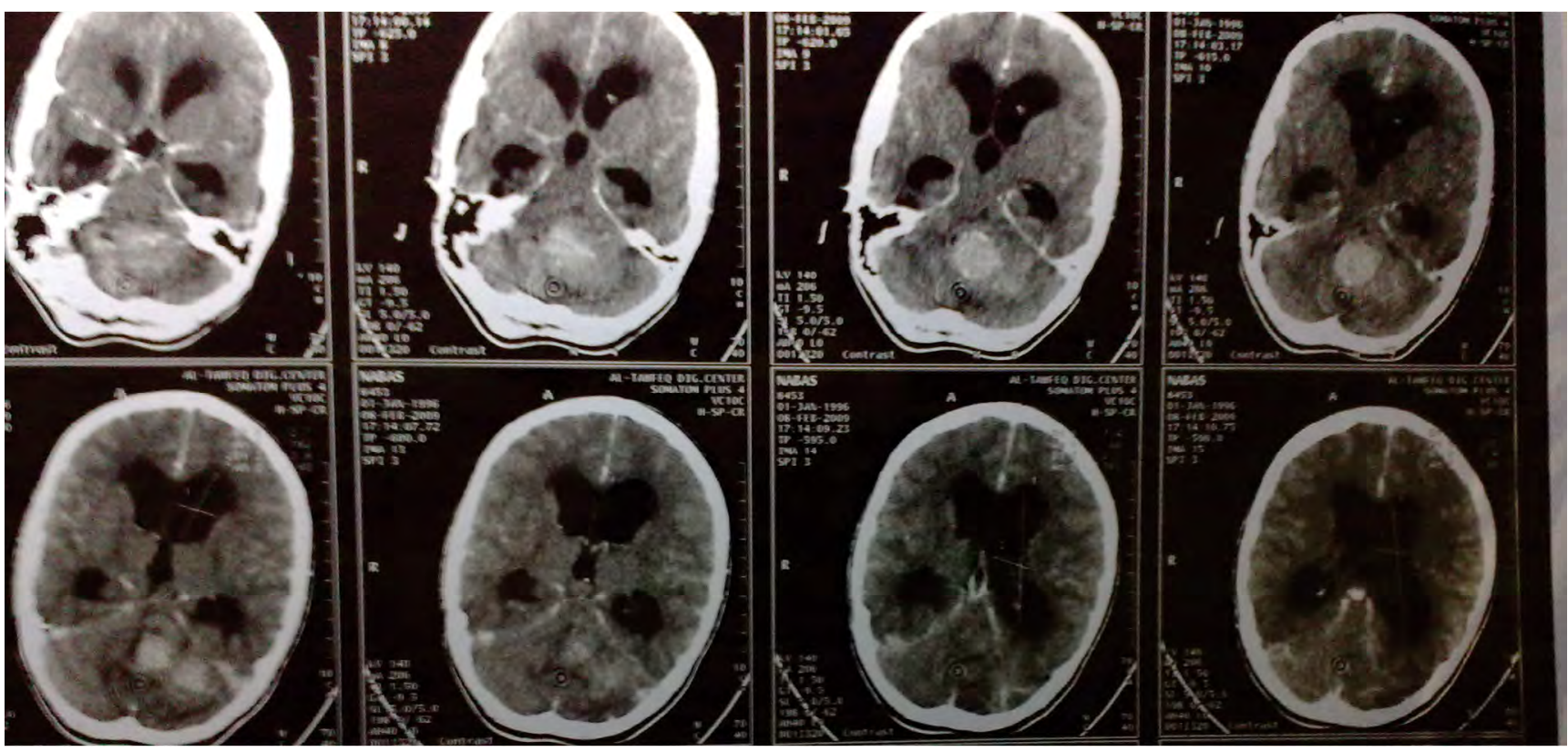

FIGURE 1. Brain CT scan of a 9 years-old female with cerebellar desmoblastic medulloblastoma 


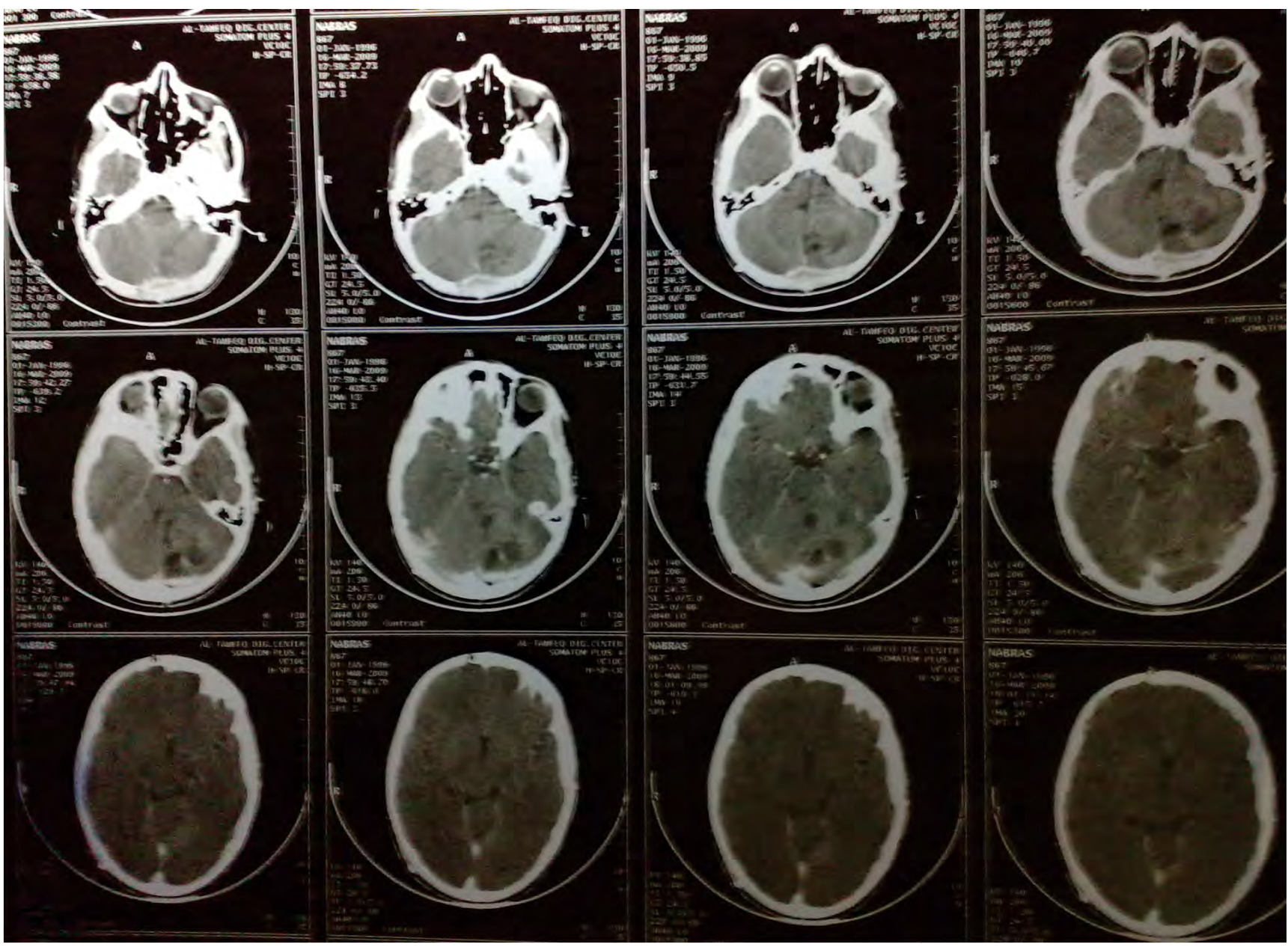

FIGURE 2. The same female child in figure 1 immediately after surgical resection, she had received radiotherapy and chemotherapy. She had suffered from recurrence of desmoblastic medulloblastoma after 2 years and died after second debulking surgery

small cells with Homer-Wright Rosette and perivascular pseudo-Rosette showing lobular pattern with dense intercellular reticulin and nodular reticulin-free zones, with moderate desmoplasia. Postoperative CT/MRI follow up imaging was performed in all children over 24 months. In all patients the craniospinal axis assessement was performed by MRI. In 2 patients there were positive spinal metastasis in the postoperative period and in one patient there was spinal dissemination preoperatively and all those 3 children died within 2-3 years after the initial diagnosis.. Postoperative radiotherapy was given for the children older than 3 years and chemotherapy of vincristine, procarbazine and methotrexate was given for all.

\section{DISCUSSIONS}

Medulloblastoma is a common cerebellar tumor and constitutes $25 \%$ of all paediatric brain tumors and has 2 peaks in childhood, 3-4 years and 6-8 years (22). The Neuropathological results for the 20 children in our study were desmoplastic medulloblastoma, some cases with poorly differentiated small cells with Homer-Wright Rosette and perivascular pseudo-Rosette showing lobular pattern with regions of dense intercellular reticulin and nodular reticulin-free zones, with moderate desmoplasia. Chelliah D et al. and Santosh Valvi et al. found that desmoplastic medulloblastoma is common in paediatric age less than 3 years and has better prognosis $(23,24)$, while Rubinstein $\mathrm{LJ}$ et al. found that the desmoplastic type occur commonly in adult patients in the cerebellar hemispheres $(40 \%$ laterally located) and that the classical type occurred in children and commonly is the midline (32).

Charles S. et al. and Chatty EM et al. concluded that nodular/desmoplastic tumors make up a large proportion of medulloblastomas presenting in the first 5 years of life; and that MBENs constitute 57\% 
of infant tumors $(35,43)$. In children aged 3-16 years, nodular/desmoplastic tumors represented only $5 \%$ of medulloblastomas, in $0-16$ years, $8 \%$ is the proportion of 350 nodular/desmoplastic variant medulloblastomas, this figure is considerably less than the $21 \%$ reported in the 1971 study by Chatty and Earle $(35,43)$. Nodular/desmoplastic medulloblastomas appeared to present at an earlier age than LC/A or classic tumors $(10,40)$. Koeller KK et al. found that medulloblastomas are pink or grey masses that may fill the 4th ventricle (25). The two main histological types of medulloblastoma are the "classical" and "desmoplastic" (31) These tumors can be desmoplastic/Nodular and MBEN types (15\%) and large cell (2-4\%) and anaplastic (15\%) tumors $(26,27,28)$. They can have paucinodular areas of reduced cell density without desmoplasia, Homer-Wright rosettes or a palisading architecture (29).

Nodular/desmoplastic medulloblastoma has a biphasic pattern consisting of reticulin-free nodules and reticulin-rich internodular areas. The tumor cells in the internodular areas are pleomorphic, densely packed, with higher mitotic index, whereas the cells in the nodular regions are sparse with bland nuclei and apoptotic cells (29). Large reniform nodules dominate the pathology of MBEN (29). Anaplastic tumors show nuclear pleomorphism, cell wrapping and high cellular proliferation, the large cell tumor is characterized by uniformly large cells, vesicular nuclei and prominent nucleoli. These 2 histologic subtypes are called the large cell/anaplastic medulloblastoma (LC/A) in the recent WHO classification (26,30).

Desmoplastic medulloblastoma is characterized by reticulin fiber formation and local infiltration of the meninges (32). In children, 7\% of desmoplastic medulloblastoma are laterally located and It constitute $10 \%$ of the childhood medulloblastomas $(9,33)$. Desmoplastic medulloblastoma is prevalent in infancy and have better outcome than classic medulloblastomas in pediatric age. Desmoplastic medulloblastoma has a heterogeneous architecture of regions with dense intercellular reticulin and nodular reticulin-free zones ("pale islands"), in which tumor cells may show a neuronal phenotype $(32,35)$. Desmoplasia is a pericellular depostion of collagen with a nodular architecture or it can be a reactive phenomenon when medulloblastoma cells invade the leptomeninges. All variants of medulloblastoma have the potential to invade the leptomeninges. The nodules cells show neurocytic differentiation with reduced growth fraction $(7,32)$. Desmoplastic medulloblastomas have a different molecular cytogenetic profile from biphasic non-desmoplastic classic and anaplastic medulloblastomas. The biphasic and nodular/desmoplastic medulloblastomas are genetically distinct, may produce neurocytic differentiation and reduced proliferation (32).

Some studies found that there are mutations of the PTCH gene, loss of heterozygosity at $9 \mathrm{q} 22$ (the PTCH locus) and activation of the SHH pathway in desmoplastic medulloblastoma (37-41). Where tissue was available, we used iFISH to examine nodular medulloblastomas, with and without desmoplasia, for chromosomal imbalance indicative of isochromosome $17 \mathrm{q}$ (i17q) and losses at $9 \mathrm{q} 22$ or $17 \mathrm{p} 13.3$, and amplification of the MYCC and MYCN genes. Loss of $17 p$ and $i(17 q)$ are characteristic of classic and anaplastic medulloblastomas and rare in nodular/desmoplastic tumors $(36,37,42)$.

Charles S. McManamy et al. found that these medulloblastoma variants can be separated on both histopathological and genetic grounds. In particular, abnormalities of chromosome 17, including $\mathrm{i}(17 \mathrm{q})$, were found exclusively in the non-desmoplastic nodular tumors (35). Loss of 9q22, whether due to an interstitial deletion or monosomy 9, was a feature of half the nodular/desmoplastic medulloblastomas. In desmoplastic histology variant, chromosome 9q loss of heterozygosity $(\mathrm{LOH})$ is detected and cannot be found in classic type $(10,40)$.

All children in our study were presented with history of one or more of the followings signs and symptoms: headaches, nausea and vomiting, gait unsteadiness, cerebellar signs including nystagmus, dysmetria, dysdiadokokinesis, ataxia and intentional tremor. O'Reilly $\mathrm{G}$ et al. found that children with medulloblastomas present with hydrocephalus, morning headache, nausea, vomiting and lethargy. Papilledema, ataxia, dysmetria and diplopia. Back pain may be the initial complaint due to spinal pathology "drop metastases" because $15-20 \%$ with medulloblastomas will have spinal metastasis at the time of diagnosis (44). Bulky, metastatic leptomeningeal disease may present with lower extremity weakness or bladder/ 
bowel incontinence from spinal cord compression, so, corticosteroids are initiated quickly with emergent radiation or surgery. Seizures are a less commonly seen presenting symptom, but do occur (45). All our cases were investigated with contrast enhanced CT and/or MRI scan imaging and revealed vividly enhanced cerebellar tumors with moderate to severe degree of hydrocephalus. Some cases were focal multinodular cerebellar hemispheric tumors in the MRI and others were midline vermian and 4th ventricular tumors.

The tumors varied in sizes from $2-5 \mathrm{~cm}$. Yachnis AT study demonstrated that tumor MRI showing large multicystic mass invading and compressing the brain stem and extending superiorly into the quadrigeminal cistern (34). Frank W. et al. found that brain CT scan and MRI show midline contrast enhancing lesion obliterating the 4th ventricle. The tumor may metastasize to the bone, so radionuclide bone scan and bone marrow aspirate are also performed (46). Majid Aljoghaiman found that the MRI imaging of medulloblastoma usually shows a compact, isointense mass, occasionally with a cystic component. Its heterogeneous contrast enhancement reflects the rich vascularity and the dense cellularity of these tumors (4). The main differential diagnosis is cerebellar astrocytoma and ependymoma. Pleomorphic xanthoastrocytoma can produce a desmoplastic reaction (47).

In this study, a midline posterior fossa craniectomy/craniotomy and tumor resection were performed under microscope after initial ventriculoperitoneal shunt or 3rd ventriculostomy for hydrocephalus. The histopathology revealed desmoplastic medulloblastoma. All patients older than 3 years were sent for brain and neuraxis irradiation then chemotherapy. The goals for operative intervention in the study of Zeltzer PM are: 1) relieve mass effect, 2) re-establish CSF circulation, 3) obtain diagnostic tissue, and 4) reduce tumor burden. Gross total resection of the primary tumor is standard of care (48).

Treatment include total surgical resection plus craniospinal irradiation. Chemotherapy is controversial (4). Subtotal surgical resection and disease dissemination are poor prognostic factors (49). Because $90 \%$ of children present with hydrocephalus, and $30 \%$ will require chronic CSF diversion, an external ventricular drain (EVD) is inserted prior to tumor resection (50). More recently, endoscopic third ventriculostomy are appropriate approach to relieve hydrocephalus. Medulloblastomas typically arising from the roof of the fourth ventricle and invade the floor of the ventricle in up to $36 \%$ of cases (51). Hydrocephalus treatment is rarely indicated $(26,27)$.

Rajesh BJ et al. and Cassie N. Kline et al. concluded that surgery frequently push the vermis posteriorly leading to division of the vermis with tumor removal. Two key approaches, telovelar and transvermian, are used to minimize damage to the vermis and deep cerebellar nuclei. The telovelar approach uses the cerebellomedullary fissure. No known functional neural tissue exists within these structures, making this approach the choice of many surgeons. For larger tumors, extended through the foramen of Magendie and thinning of the vermis and cerebellar peduncles, the tumor should be debulked to allow for partial restoration of normal anatomy $(29,45)$. For the transvermian approach, the inferior vermis is split vertically. Generally, the telovelar approach is preferred given the proposed relationship between splitting the vermis and development of cerebellar mutism syndrome or posterior fossa syndrome, which is speech apraxia, hypotonia, ataxia, emotional lability and cranial nerve deficits $(30,52)$ Cerebellar mutism occurs in $30 \%$ of medulloblastoma resection (30).

In our study on 20 children, 4 patients developed such akinetic mutism, in all those, we had split the midline cerebellar vermis. One popular theory suggests that the cause is splitting of the inferior vermis $(30,52)$. The dentatothalamic pathway may play a role. Most patients regain some speech but may experience persistent lack of full speech, abnormal tone, and balance problems $(30,53)$. In our study all the cases required medical steroid therapy (dexamethasone $4 \mathrm{mg}$ every 6 hours) for hydrocephalus and raised intracranial pressure; either ventriculoperitoneal shunt or endoscopic 3rd ventriculostomy were performed, in one child with midline cerebellar medulloblastoma, we performed tumor resection without permanent shunt and we needed only transient postoperative EVD for 5 days postoperatively to relieve postoperative hydrocephalus.

Cassie N. Kline found that when immediate surgical resection is not possible, initiation of corticos- 
teroids to decrease tumor-associated edema and/or surgical placement of an external ventricular drain or ventriculoperitoneal shunt may be considered (45). Lee and others identified factors associated with permanent shunting include young age, extensive preoperative ventricular dilatation, and large tumors (27). We sent all patients older than 3 years for brain and neuraxis irradiation then chemotherapy. In all patients the craniospinal axis assessement was performed by MRI. In 2 patients there were positive spinal metastasis in the postoperative period and in one patient there was spinal dissemination preoperatively. Postoperative radiotherapy was given for all the children older than 3 years and all received chemotherapy of vincristine, procarbazine and methotrexate. Packer RJ et al. concluded that the dose of cranio-spinal irradiation is 3,600 cGy.

In children below 8 years, the treatment with the higher dose neuraxis radiation cause intellectual morbidity. Children with medulloblastoma were treated with cranio-spinal irradiation and CCNU, vincristine and cisplatin chemotherapy. The 5-year progression-free survival was $70 \%$ (54). Recent studies have proven efficacy of intensive chemotherapies in young children under the age of three, in whom craniospinal irradiation (CSI) is avoided or delayed to prevent neurological deficits (55). Clinical parameters such as age, metastatic stage at initial diagnosis, or extent of surgery are essential for stratification of patients into low- and high-risk medulloblastoma therapy groups (48). In this study, the median postoperative follow-up time was 24 months, four patients developed transient postoperative akinetic mutism and improved after few weeks postoperatively. All those 4 patients were operated for midline vermian/4th ventricular medulloblastoma. The neuropathological diagnosis was desmoplastic medulloblastoma. In all patients the craniospinal axis assessement was performed by MRI. In 2 patients there were positive spinal metastasis in the postoperative period and in one patient there was spinal dissemination preoperatively, all those 3 children died within 2-3 years after the initial diagnosis.

Charles S. et al. found that nodular/desmoplastic medulloblastomas have a better prognosis than classic medulloblastomas and present at an earlier age (35). Early and recent studies found improved survival in desmoplastic medulloblastoma (43). While other series in adults, reported no difference in the outcome of patients with desmoplastic versus classic medulloblastoma $(56,57)$. Infants and young children with desmoplastic histology have better prognosis compared with older children (10). The German Pediatric Brain Tumor Study showed better 5 years outcome survival (OS) for infants with desmoplastic medulloblastoma (95\%) than for classic medulloblastoma (41\%) (35). The nodular/ desmoplastic variant, including the MBEN have better outcomes; and the LC/A variant have worse outcomes than the classic variant $(10,35)$. Good outcome medulloblastomas with nuclear accumulation of $\beta$-catenin and poor outcome medulloblastomas with loss of 17p or MYC amplification (36). Other childhood nodular/desmoplastic medulloblastomas, whether presenting in infancy or later, are associated with a relatively good outcome, when compared with classic or LC/A tumors $(35,43)$. In a retrospective analysis of 66 patients, desmoplastic medulloblastoma patients fare better than the classic counterparts (58-61). In several previous studies, both the initial spread and dissemination of disease and postoperative tumor residues significantly determined outcome and prognosis in patients with classic medulloblastoma (11). In the study of Stefan Rieken et al., outcome was influenced by the success of combined first line therapies rather than the initial stage of disease or extent of surgery (62). All patients with relapsing tumor either died from medulloblastoma or were soon lost to further follow-up, most likely indicating progression to death. Initial locoregional infiltrative and metastatic disease or postoperative residual tumor did not significantly influence outcome. Tumor features at initial diagnosis such as lateral versus medial location, infiltration of the fourth ventricle, metastatic disease, extent of resection or age did not affect therapy outcome (62). However, spinal recurrence of disease significantly impaired outcome. Radical surgery to a reasonable extent followed by radiotherapy and adjuvant chemotherapy provide the best results (62).

The five-year survival for medulloblastoma in adults has been estimated to be $46 \%$ to $78 \%$ as per reports by Skolyszewski and Glinski (4). In some reports, infiltration of the fourth ventricle possibly enhance the risk of tumor dissemination. This is 
mainly due to less complete resection and closer proximity to spinal fluid circulation $(63,64)$. Dissemination of medulloblastoma within CSF pathways is characteristic of this tumor and signifies bad prognosis (4).

\section{CONCLUSIONS}

Desmoplastic medulloblastoma is common adult medulloblastoma and it is uncommon paedi- atric variety. However, its incidence is more in infant and young children compared to older children. It has rather better prognosis compared to the classical and anaplastic medulloblastoma. Total surgical resection followed by craniospinal irradiation and/or chemotherapy and the absence of initial spinal and CSF metastasis improve the 5 years outcome survival and prognosis.

Conflict of interest: none declared Financial support: none declared

\section{REFERENCES}

1. McNeil DE, Cote TR, Clegg L, Rorke LB. Incidence and trends in pediatric malignancies medulloblastoma/primitive neuroectodermal tumor: A SEER update. Surveillance Epidemiology and End Results. Med Pediatr Oncol. 2002;39:190-194.

2. Ries L, Kosary C, Hankey B. SEER cancer statistical review, 1973-1994. National Cancer Institute, SEER Program NIH Publication Number 97-2789, 1997.

3. Raaf J, Kernohan JW. Relation of abnormal collections of cells in posterior medullary velum of cerebellum to origin of medulloblastoma. Arch NeurPsych. 1944;52(3):163-169.

4. Aljoghaiman M, Taha MS, Abdulkader MM. Cerebellar Medulloblastoma in Middle-to-Late Adulthood. Case Rep Pathol. 2018 Jan 31; 2018:5425398.

5. Burger PC, Grahmann FC, Bliestle A, Kleihues P (1987) Differentiation in the medulloblastoma. A histological and immunohistochemical study. Acta Neuropathol (Berl) 73:115-123.

6. Eberhart CG, Kepner JL, Goldthwaite PT, Kun LE, Duffner PK, Friedman HS, Strother DR, Burger PC (2002) Histopathologic grading of medulloblastomas: a Pediatric Oncology Group study. Cancer 94:552-560.

7. Ellison D. Classifying the medulloblastoma: Insights from morphology and molecular genetics. Neuropathol Appl Neurobiol. 2002; 28:257-282.

8. Giordana MT, Schiffer P, Lanotte M, Girardi P, Chio A. Epidemiology of adult medulloblastoma. Int J Cancer 1999;80:689-692.

9. Maleci A, Cervoni L, Delfini R. Medulloblastoma in children and in adults: A comparative study. Acta Neurochir. (Wien) 1992;119:62-67.

10. Rutkowski S, Bode U, Deinlein F, Ottensmeier H, Warmuth-Metz M, Soerensen N, Graf N, Emser A, Pietsch T, Wolff JE, Kortmann RD, Kuehl J. Treatment of early childhood medulloblastoma by postoperative chemotherapy alone. N Engl J Med 2005; 352:978-986.

11. Chan AW, Tarbell NJ, Black PM, Louis DN, Frosch MP, Ancukiewicz M, Chapman P, Loeffler JS. Adult medulloblastoma: Prognostic factors and patterns of relapse. Neurosurgery 2000;47(3):623-631.

12. Giangaspero F, Perilongo G, Fondelli MP, Brisigotti M, Carollo $C$, Burnelli R, Burger PC, Garre ML. Medulloblastoma with extensive nodularity: A variant with favorable prognosis. J Neurosurg. 1999; 91:971-977.

13. Suresh TN, Santosh V, Yasha TC, Anandh B, Mohanty A, Indiradevi B, Sampath S, Shankar SK. Medulloblastoma with extensive nodularity: a variant occurring in the very youngclinicopathological and immunohistochemical study of four cases. Childs Nerv Syst. 2004;20:55-60.

14. Eberhart CG, Kepner JL, Goldthwaite PT, Kun LE, Duffner PK, Friedman HS, Strother DR, Burger PC. Histopathologic grading of medulloblastomas: A Pediatric Oncology Group study. Cancer 2002;94:552-560.

15. McManamy CS, Lamont JM, Taylor RE, Cole M, Pearson AD, Clifford $\mathrm{SC}$, Ellison DW. Morphophenotypic variation predicts clinical

behavior in childhood non-desmoplastic medulloblastomas. J Neuropathol Exp Neurol. 2003;62:627-632.

16. Louis DN, Ohgaki $\mathrm{H}$, Wiestler OD et al. The 2007 WHO classification of tumours of the central nervous system. Acta Neuropathol 2007; 114(2):97-109.

17. Gajjar AJ, Robinson GW. Medulloblastoma-translating discoveries from the bench to the bedside. Nat Rev Clin Oncol 2014; 11(12):714-22.

18. Tammy Hennika, Sridharan Gururangan. Childhood medulloblastoma: Current and future, treatment strategies. Taylor and Francis 2015;11:1299-1317.

19. Louis DN, Perry A, Reifenberger G, von Deimling A, FigarellaBranger D, Cavenee WK, Ohgaki H, Wiestler OD, Kleihues P, Ellison DW. The 2016 World Health Organization Classification of Tumors of the Central Nervous System: A summary. Acta Neuropathol. 2016 Jun; 131(6):803-20.

20. Villani A, Malkin D, Tabori U. Syndromes predisposing to pediatric central nervous system tumors: lessons learned and new promises. Curr Neurol Neurosci Rep 2012;12(2):153-64.

21. Rorke LB, Gilles FH, Davis RL, Becker LE. Revision ofthe World Health Organization classification of brain tumors for childhood brain tumors. Cancer 1985;56:1869-86.

22. Kaufman BA. Medulloblastoma. In : Winn HR, editors. Youmans Neurological Surgery.Vol 3, Book 3. Saunders, Philadelphia, 2004, p. 3639-54.

23. Chelliah D, Mensah Sarfo-Poku C, Stea BD, Gardetto J, Zumwalt J. Medulloblastoma with extensive nodularity undergoing posttherapeutic maturation to a gangliocytoma: A case report and literature review. Pediatr Neurosurg. 2010;46(5):381-384.

24. Valvi S, Ziegler DS. Ganglioglioma Arising From Desmoplastic Medulloblastoma: A Case Report and Review of Literature. Pediatrics. 2017 Mar;139(3).

25. Koeller KK, Rushing EJ. From the archives of the AFIP Medulloblastoma: A comprehensive review with radiologic-pathologic correlation. Radiographics. 2003;23(6):1613-1637.

26. Albright AL. The value of precraniotomy shunts in children with posterior fossa tumors. Clin Neurosurg. 1983;30:278-285.

27. Lee $\mathrm{M}$, Wisoff $\mathrm{JH}$, Abbott $\mathrm{R}$ et al. Management of hydrocephalus in children with medulloblastoma: prognostic factors for shunting. Pediatr Neurosurg. 1994;20(4):240-247.

28. El-Gaidi MA, El-Nasr AH, Eissa EM. Infratentorial complications following preresection CSF diversion in children with posterior fossa tumors. J Neurosurg Pediatr. 2015;15(1):4-11.

29. Rajesh BJ, Rao BR, Menon G et al. Telovelar approach: Technical issues for large fourth ventricle tumors. Childs Nerv Syst. 2007; 23(5):555-558.

30. Gudrunardottir T, Sehested A, Juhler M et al. Cerebellar mutism: Review of the literature. Childs Nerv Syst. 2011;27(3):355-363.

31. Giangspero F, Bigner SH, Kleihues P, Pietsch T, Trojanowski JQ. Medulloblastoma. In: Kleihues P, Cavenee WK, eds. Pathology and 
Genetics of Tumors of the Nervous System. Lyon: IARC Press; 2000. pp. 129-37.

32. Rubinstein LJ, Northfield DWC. The medulloblastoma and the so-called "arachnoidal cerebellar sarcoma". Brain 1964;87:379-412.

33. Provias JP, Becker LE. Cellular and molecular pathology of medulloblastoma. J Neurooncol 1996;29:39-43.

34. Yachnis AT, Rorke LB, Biegel JA, Perilongo G, Zimmerman RA, Sutton LN. Desmoplastic primitive neuroectodermal tumor with divergent differentiation. Am J Surg Pathol. 1992;16:998-1006.

35. McManamy CS, Pears J, Weston CL, Hanzely Z, Ironside JW, Taylor RE, Grundy RG, Clifford SC, Ellison DW; Clinical Brain Tumour Group. Nodule formation and desmoplasia in medulloblastomasdefining the nodular/desmoplastic variant and its biological behavior. Brain Pathol. 2007 Apr;17(2):151-64.

36. Lamont JM, McManamy CS, Pearson AD, Clifford SC, Ellison DW. Combined histopathological and molecular cytogenetic stratification of medulloblastoma patients. Clin Cancer Res. 2004;10:5482-5493.

37. Nicholson JC, Ross FM, Kohler JA, Ellison DW. Comparative genomic hybridization and histological variation in primitive neuroectodermal tumours. Br J Cancer 1999;80:1322-1331.

38. Pietsch T, Waha A, Koch A, Kraus J, Albrecht S, Tonn J, Sorensen N, Berthold F, Henk B, Schmandt N, Wolf HK, von Deimling A, Wainwright B, Chenevix-Trench G, Wiestler OD, Wicking C. Medulloblastomas of the desmoplastic variant carry mutations of the human homologue of Drosophila patched. Cancer Res. 1997; 57:2085-2088.

39. Pomeroy SL, Tamayo P, Gaasenbeek M, Sturla LM, Angelo M, McLaughlin ME, Kim JY, Goumnerova LC, Black PM, Lau C, Allen JC et al. Prediction of central nervous system embryonal tumour outcome based on gene expression. Nature 2002;415:436-442.

40. Schofield D, West DC, Anthony DC, Marshal R, Sklar J. Correlation of loss of heterozygosity at chromosome $9 \mathrm{q}$ with histological subtype in medulloblastomas. Am J Pathol. 1995;146:472-480.

41. Thompson MC, Fuller C, Hogg TL, Dalton J, Finkelstein D, Lau CC, Chintagumpala M, Adesina A, Ashley DM, Kellie SJ, Taylor MD, Curran T, Gajjar A, Gilbertson RJ. Genomics identifies medulloblastoma subgroups that are enriched for specific genetic alterations. J Clin Oncol. 2006;24:1924-1931.

42. Ehrbrecht A, Muller U, Wolter M, Hoischen A, Koch A, Radlwimmer B, Actor B, Mincheva A, Pietsch T, Lichter P, Reifenberger G, Weber RG. Comprehensive genomic analysis of desmoplastic medulloblastomas: identification of novel amplified genes and separate evaluation of the different histological components. J Pathol. 2006;208:554-563.

43. Chatty EM, Earle KM. Medulloblastoma. A report of 201 cases with emphasis on the relationship of histologic variants to survival. Cancer 1971;28:977-983.

44. O'Reilly G, Hayward R, Harkness W. Myelography inthe assessment of children with medulloblastoma. Br J Neurosurg 1993;7:183-8.

45. Cassie N. Kline, Roger J. Packer, Eugene I. Hwang, David R. Raleigh, Steve Braunstein, Corey Raffel, Pratiti Bandopadhayay, David A. Solomon, Mariam Aboian, Soonmee Cha, Sabine Mueller. Case-based review: Pediatric medulloblastoma. Neuro-Oncology Practice 2017;4(3):138-150.

46. Frank W. Drislane, Michael Benatar, Bernard S. Chang, Juan A. Acosta, John E. Croom, Andrew Tarulli, Louis R. Caplan. Blueprints neurology. Second edition. Chapter 19, page 132.

47. Sugita Y, Kepes JJ, Shigemori M et al. Pleomorphic xanthoastrocytoma with desmoplastic reaction: angiomatous variant: report of two cases. Clin Neuropathol. 1990;9:271-280.

48. Zeltzer PM, Boyett JM, Finlay JL et al. Metastasis stage, adjuvant treatment, and residual tumor are prognostic factors for medulloblastoma in children: Conclusions from the Children's Cancer Group 921 randomized phase III study. J Clin Oncol. 1999; 17(3):832-845.

49. Le QT, Weil MD, Wara WM, Lamborn KR, Prados MD, Edwards MS, Gutin PH. Adult medulloblastoma: an analysis of survival and prognostic factors. Cancer J Sci Am. 1997 Jul-Aug;3(4):238-45.

50. Albright A. Medulloblastomas. In: Albright A, Pollack I, Adelson P, editors. Principles and practice of pediatric neurosurgery. New York: Theime, 1999; 591-608.

51. Park T, Hoffman H, Hendrick B, Humphreys R, Becker L. Medulloblastoma. Clinical presentation and management:experience at the Hospital For Sick Children,Toronto, 1950-1980. J Neurosurg 1983;58:543-52.

52. Rekate HL, Grubb RL, Aram DM et al. Muteness of cerebellar origin. Arch Neurol. 1985;42(7):697-698.

53. Palmer SL, Hassall T, Evankovich $\mathrm{K}$ et al. Neurocognitive outcome 12 months following cerebellar mutism syndrome in pediatric patients with medulloblastoma. Neuro Oncol. 2010;12(12):1311-1317.

54. Packer RJ, Sutton LN, Elterman R, Lange B, Goldwein J,Nicholson HS et al. Outcome for children with medulloblastomatreated with radiation and cisplatin, $\mathrm{CCNU}$, and vincristine chemotherapy. J Neurosurg 1994;81:690-8.

55. Rutkowski S, Cohen B, Finlay J, Luksch R, Ridola V, ValteauCouanet D, Hara J, Garre ML, Grill J. Medulloblastoma in young children. Pediatr Blood Cancer. 2010 Apr;54(4):635-7.

56. Carrie C, Lasset C, Blay JY et al. Medulloblastoma in adults: Survival and prognostic factors. Radiother Oncol. 1993;29:301-307.

57. Hubbard JL, Scheithauer BW, Kispert DB et al. Adult cerebellar medulloblastomas: the pathological, radiographic, and clinical disease spectrum. J Neurosurg. 1989;70:536-544.

58. Tait DM, Thornton-Jones H, Bloom HJ, Lemerle J, Morris-Jones P. Adjuvant chemotherapy for medulloblastoma: The first multi-centre control trial of the International Society of Paediatric Oncology (SIOP I). Eur J Cancer 1990, 26(4):464-469.

59. Evans AE, Jenkin RD, Sposto R, Ortega JA, Wilson CB, Wara W, Ertel IJ, Kramer S, Chang CH, Leikin SL et al. The treatment of medulloblastoma. Results of a prospective randomized trial of radiation therapy with and without $\mathrm{CCNU}$, vincristine, and prednisone. J Neurosurg. 1990, 72(4):572-582.

60. Jenkin D, Goddard K, Armstrong D, Becker L, Berry M, Chan H, Doherty M, Greenberg M, Hendrick B, Hoffman $\mathrm{H}$ et al. Posterior fossa medulloblastoma in childhood: Treatment results and a proposal for a new staging system. Int J Radiat Oncol Biol Phys. 1990 Aug;19(2):265-74.

61. Rieken S, Mohr A, Zipp L, Lindel K, Debus J, Combs SE. Behandlungsergebnisse und prognostische Faktoren nach Bestrahlung von Medulloblastomen. Onkologie 2010, 33(Suppl. 2):55-58.

62. Rieken S, Gaiser T, Mohr A, Welzel T, Witt O, Kulozik AE, Wick W, Debus J, Combs SE. Outcome and prognostic factors of desmoplastic medulloblastoma treated within a multidisciplinary treatment concept. BMC Cancer. 2010 Aug 23;10:450.

63. Carrie C, Lasset C, Alapetite C, Haie-Meder C, Hoffstetter S, Demaille MC, Kerr C, Wagner JP, Lagrange JL, Maire JP et al. Multivariate analysis of prognostic factors in adult patients with medulloblastoma. Retrospective study of 156 patients. Cancer 1994 , 74(8):2352-2360.

64. Herrlinger U, Steinbrecher A, Rieger J, Hau P, Kortmann RD, Meyermann R, Schabet M, Bamberg M, Dichgans J, Bogdahn U et al. Adult medulloblastoma: prognostic factors and response to therapy at diagnosis and at relapse. J Neurol 2005, 252(3):291-299. 